\title{
EDITORIAL
}

\section{¿Cómo se hace un líder?}

\section{How to become a leader?}

\author{
Patrizio Petrone \\ Coeditor, Revista Colombiana de Cirugía \\ Department of Surgery, NYU Langone Health - NYU Winthrop Hospital; Associate Professor of Surgery, \\ NYU Long Island School of Medicine; Mineola, New York, USA
}

La palabra líder proviene del inglés leader y, por definición, se refiere a la persona que actúa como guía o jefe de un grupo. Para que su liderazgo sea efectivo, los demás integrantes deben reconocer sus capacidades. El líder tiene la facultad de influir en otros sujetos, y su conducta o sus palabras logran incentivar a los miembros de un grupo para que trabajen en conjunto por un objetivo común. Comenzaremos presentando las diversas clasificaciones de líder, que incluyen:

- Líder creativo: desafía procesos, inspira una visión compartida, faculta a otros, modela con el ejemplo, y despierta pasión y entusiasmo en el trabajo.

- Líder diseñador: la esencia del diseño consiste en ver cómo las partes se articulan para desempeñarse como un todo. La tarea crucial para los líderes de organizaciones inteligentes se relaciona con la integración de la visión, el aprendizaje en equipo, el dominio personal, los modelos mentales y el pensa- miento sistemático, es decir, la integración de todas las disciplinas del aprendizaje.

- Líder transformador: es el formulador de valores y creador de significados, creador de finalidad institucional, capaz de imbuir valores. Posee una fuerte dosis de credibilidad (conocimientos y experiencia) y entusiasmo (creer en lo imposible). Es, además, un experto en la promoción y protección de valores. Su mensaje se basa en ser los mejores, excelencia académica, servicio al cliente, etc. Es un arquitecto social.

Cada uno de estos atributos involucran al líder en una serie de actividades que desarrolla en la vida cotidiana de la organización, de tal manera que logra fortalecer en sus colaboradores una serie de conductas y actitudes propias de la creatividad. El desafiar los procesos implica buscar continuamente oportunidades para crecer, cambiar, innovar y mejorar; ser capaz de experimentar tomando riesgos y, de ese modo, apren-

Palabras clave: cirugía general; habilidades; liderazgo; comunicación; clasificación.

Key words: general surgery; skills; leadership; communication; classification.

Fecha de recibido: 22/10/2019 - Fecha aceptación: 24/10/2019

Correspondencia: Patrizio Petrone P, MD, PhD, MPH, MHSA, FACS; Director of Surgical Research, Program Director of the International Research Fellowship; Department of Surgery, NYU Winthrop Hospital; Associate Professor of Surgery, NYU Long Island School of Medicine; 222 Station Plaza North, Suite 300; Mineola, New York, 11501, USA

Correo electrónico: patrizio.petrone@gmail.com y patrizio.petrone@nyulangone.org

Citar como: Petrone P. ¿Cómo se hace un líder? Rev Colomb Cir. 2020;35:14-6. https://doi.org/10.30944/20117582.577

Este es un artículo de acceso abierto bajo una Licencia Creative Commons - BY-NC-ND https://creativecommons.org/licenses/by-nc-nd/4.0/deed.es 
der de los errores. Por ejemplo, el líder creativo construye una visión común de un futuro promisorio con la colaboración de los miembros de su equipo, apelando a sus valores, intereses, deseos y sueños. Establece las condiciones para que todos tengan la voluntad de invertir sus talentos y esfuerzos para lograr dicha visión, ya que les resulta atractiva e implica un reto, por lo que les demanda su aporte creativo.

La capacidad para facultar a otros es un atributo importante que el líder pone en práctica promoviendo metas cooperativas y construyendo sobre una base de confianza. Facultar no es solo delegar, sino también, liberar el potencial de cada uno de los colaboradores. Facultar implica fortalecer a los individuos, compartiendo información a la vez que se amplía su poder de decisión y su visibilidad. Así, modela con el ejemplo, comportándose de manera coherente con sus valores expresados. Actúa de acuerdo con lo dicho, es capaz de establecer una conexión entre su interior y el ambiente externo. Como parte de sus actividades, el líder planea y establece las condiciones para que se den pequeñas victorias que promuevan un progreso constante. Despierta pasión y entusiasmo en el trabajo, reconociendo las contribuciones individuales para el éxito de cada proyecto y celebrando los logros del equipo en forma permanente.

A su vez, el líder debe afrontar diversos retos, entre ellos:

- promover la innovación en las tareas;

- desencadenar los talentos potenciales de cada uno de sus colaboradores;

- administrar el cambio, en lugar de solo reaccionar ante él;

- generar condiciones para retener a los individuos con los mejores talentos;

- favorecer una fuerza de trabajo, cargada de energía y comprometida;

- alinear el desarrollo personal de cada individuo, sus talentos y capacidades con un desempeño altamente competitivo;

- generar un sentido de urgencia para facilitar actitudes positivas hacia el cambio, y

- mejorar la calidad.
El líder es alguien capaz de hacer que las cosas sucedan en su vida personal o profesional, y tiene la habilidad de influir en otros para que quieran actuar con un propósito que les resulte deseable o alcanzable con base en sus talentos y en el compromiso de todos.

John P. Kotter sugiere que "los líderes deben poder comunicar su visión para implementar el cambio y obtener entendimiento e interés en cinco minutos". La mejor visión en el mundo no tiene valor si es un gran secreto. Los líderes deben comunicar su visión de manera efectiva mediante acciones.

Las organizaciones actuales se encuentran administradas en exceso y carentes de liderazgo. La administración es la respuesta a la complejidad de las grandes organizaciones, mientras que el liderazgo se relaciona con la capacidad para enfrentar y producir cambios, creando visión por medio de estrategias.

De tal forma, que todos pueden ser líderes, aunque muy pocos lleguen a serlo, debido a que la mayoría de las personas son prisioneras de su propia inercia, que les impide cambiar y desarrollar su potencial. Los líderes son importantes porque el éxito o el fracaso de toda organización descansa en la calidad que se percibe de ellos, y porque el cambio y la agitación de los años recientes han hecho desaparecer los caminos claros y definidos. Por ello, es imperativo contar con visionarios que guíen a las sociedades.

No existe un líder típico, cada uno tiene su tipo y estilo únicos. Sin embargo, los líderes poseen una visión orientadora, una idea clara de lo que desean hacer y la fortaleza para ejecutar esa visión, a pesar de los inconvenientes que se puedan presentar en su camino. Expresan pasión por lo que hacen y la comunican en formas que inspiran a los demás. También, deben poseer integridad, la que se expresa de diferentes maneras, entre ellas:

Se conocen a sí mismos: los seres humanos comienzan a ser líderes en el momento en que deciden por sí mismos cómo quieren ser, dejando atrás lo que otros opinen. Esto requiere de mucha 
determinación y coraje, ya que deben distinguir entre quiénes son y quiénes quieren llegar a ser. Conocen el entorno: los verdaderos líderes están obsesionados con conocer el mundo tanto como se conocen a sí mismos. Este conocimiento proviene de viajes, una vida privada satisfactoria, contactos clave con grupos y mentores, y una amplia y continua educación.

Siguen sus instintos: con el objetivo de simplificar sus vidas, los seres humanos se empeñan en reducir los riesgos que se pueden presentar en su camino. Quienes promueven la simplicidad ven la realidad como mecánica, segmentada y racional cuando, en realidad, es orgánica, completa y ambigua.

Permiten sugerencias: una vez dominadas las habilidades de liderazgo mencionadas, la persona debe expresarse como un líder. Para ello, reflexiona, aprendiendo así de experiencias pasadas.

Surcan el caos: los líderes operan en ambientes caóticos e impredecibles. Deben aceptar que aprenden a medida que actúan. Deben aprender a reconocer cuáles son los retos, qué tareas no están programadas y qué trabajos se están realizando por primera vez.
Ponen a la gente de su lado: el carisma no es una cualidad esencial para el liderazgo. Muchos líderes sin carisma logran inspirar confianza y lealtad, aunque quienes lo poseen logran reunir mayor apoyo.

Controlan el mañana: convertirse en un líder es una aventura y un descubrimiento que dura toda la vida.

Para llegar a ser un líder genuino, hay que dominar el contexto del ambiente de liderazgo, aprender y emplear los ingredientes básicos del liderazgo, conocer su verdadero ser, reflexionar y resolver. En consecuencia, es necesario demostrar constancia en los propósitos, ser confiable y transmitir integridad.

\section{Lecturas recomendadas}

- Hersey P, Blanchard KH. So you want to know your leadership style? Training and Development Journal. I997;28:22-37.

- $\quad$ Bennis W. On becoming a leader. New York: Perseus Publishing; 2009.

- $\quad$ Kotter JP. Leading Change: Why transformation efforts fail? Harvard Business Review. March-April, 1995. 